\title{
Notas sobre fronteiras, pós-colonialismo e pensamento fronteiriço
}

\author{
Notas sobre fronteras, post-colonialismo y pensamiento fronterizo
}

\author{
Notes about borders, post-colonialism and borderer thought
}

Fábio de Lima ${ }^{1}$

\begin{abstract}
Resumo
O termo fronteira tem adquirido uma série de acepções na atualidade. Uma delas indica a necessidade de compreender a fronteira a partir de relações de poder, ambiguidades e hibridismos nas diversas situações que nela se encontram. O objetivo deste artigo, é analisar os aspectos do termo fronteira na abordagem denominada pós-colonial em associação com o termo pensamento fronteiriço. Em suma, as abordagens pós-coloniais revelam duras críticas às noções de desenvolvimento, as formas de saberes eurocêntricos, as desigualdades entre os sexos, as hierarquias raciais, as desigualdades nas periferias do sistema-mundo, entre outros.
\end{abstract}

Palavras-chave: Fronteira, pós-colonialismo, pensamento fronteiriço.

\section{Resumen}

El término frontera ha adquirido una serie de acepções en la actualidad. Una de ellas indica la necesidad de comprender la frontera a partir de relaciones de poder, ambiguidades e hibridismos en las diversas situaciones que en ella se encuentran. El objetivo de este artículo es analizar los aspectos del término frontera en el abordaje denominado post-colonial en asociación con el término pensamiento fronterizo. En resumen, los abordajes post-coloniais revelan duras críticas a las nociones de desarrollo, las formas de saberes eurocêntricos, las desigualdades entre los sexos, las jerarquías raciales, las desigualdades en las periferias del sistema-mundo, entre otros.

Palabras Claves: Frontera, post-colonialismo, pensamiento fronterizo.

\begin{abstract}
The border term has acquired a series of meanings nowadays. One of them indicates the need to understand the border as from of power relations, ambiguities and hybrids in a variety in different situations found in it. The aim of this article is to analyze aspects of term frontier in post-colonial approach called border in association with the border thinking. In short, post-colonial approaches reveal harsh criticism to the notions of development, ways of knowing Eurocentric, gender inequalities, racial hierarchies, inequalities in the peripheries of the world-systems, among others.
\end{abstract}

Keywords: Border, Post-Colonialism, Borderer thought.

\section{Introdução}

Para o imaginário social, a fronteira apresenta-se como um limite que delimita/demarca o espaço geográfico dividindo o território em diversas Nações. Existe nessa perspectiva uma orientação geopolítica, resumindo a fronteira a uma linha divisória (limite)

\footnotetext{
${ }^{1}$ Bacharel e mestrando em Geografia; Universidade Federal da Grande Dourados - UFGD; Dourados, Mato Grosso do Sul, Brasil; fabio_lima42@ hotmail.com.
} 
político-administrativa controlada pelos Estados. Neste caso, devemos considerar as fronteiras como o resultado de relações de poder entre os povos ou grupos sociais.

A partir dos anos 1960, o termo fronteira passa a adquirir novos sentidos nas pesquisas antropológicas, passaram a ser compreendidas como zonas de contato de conflitos interétnicos representando as diferenças simbólicas entre o "nós" e "eles". Desde então, a fronteira tem expandido seus significados para múltiplos sentidos e designações.

Ocorre que, em meados dos anos 1970, os estudos sobre fronteiras expandiram-se a partir de perspectivas transdisciplinares, principalmente pelo viés de estudos feministas, culturais e pós-coloniais (ALBUQUERQUE, 2010). Essas pesquisas indicavam o imperativo de refletir sobre as relações de poder, as ambiguidades e os hibridismos nas diversas situações de fronteira (ALBUQUERQUE, 2012).

Neste artigo, pensamos que as fronteiras podem ser abordadas a luz das teorias que confluem no sentido do pós-colonialismo (ALBUQUERQUE, 2010; PORTO-GONCALVES, 2011; MIGNOLO, 2003; GROSFOGUEL).

Por sua vez, a ideia de pensamento fronteiriço, depara-se em associação a um paradigma de fronteira que vem se desenvolvendo em cooperação com o pensamento descolonial latino-americano.

\section{Algumas considerações sobre fronteira}

A etimologia da palavra fronteira, vem do latim "frons" que significa "parte mais à frente" ou de acordo com Machado (1998) “o que está na frente”. Segundo o dicionário Houaiss da Língua Portuguesa, fronteira teria vindo do francês frontier, que designava a ação de um soldado posicionando-se na frente do inimigo. Sendo que há uma outra definição, referindo- se aos limites do território de um estado (HOUAISS, 2007). Assim, a gênese da palavra fronteira nasceu de forma espontânea, representando a margem do mundo habitado, mas "na medida que os padrões de civilização foram se desenvolvendo acima do nível de subsistência, as fronteiras entre ecúmenos tornaram-se lugares de comunicação e, por conseguinte, adquiriram um caráter político (MACHADO, 1998, p.41).

A linearização da fronteira é uma invenção do Estado moderno, culminando nas fronteiras "rígidas" que se tornaram "impenetráveis" constituída por "muros" (RAFFESTIN, 1933), a exemplo o muro de Berlim, muro da Cisjordânia ou de Israel, muro fronteiriço Estados Unidos-México. Fatores ideológicos conduzem os Estados modernos a criarem uma série de mecanismos de vigilância, controle e enquadramentos - ou, como nas palavras de 
Michel Foucault (2008) para "vigiar e punir" - para assegurar a manutenção do sistema e de suas fronteiras.

\begin{abstract}
Neste sentido, o território necessita sempre de algum tipo de fronteira, ou melhor, de limite, ainda que vivamos um tempo, especialmente de 1989 - com a queda do muro de Berlim - para cá, em que muitos discursos são feitos em nome do debilitamento das fronteiras. Entretanto, o que parece paradoxal, vemos também, hoje, claramente, o aparecimento de um processo inverso, o de um novo fortalecimento dos muros, das cercas ou, se quisermos, das "fronteiras", num determinado sentido (HAESBAERT, 2009, p.56-57).
\end{abstract}

A interpretação que pode ser feita a partir das análises anteriores, revela que o instinto geográfico de constituir limites ou fronteiras (aqui entram as imaginárias) estabelecendo uma "linha” se separa o "nós" (civilização) do "outro" (barbárie). Mas sempre fica a pergunta: quem são o "nós" e quem é o "outro"?

Nessa perspectiva, a concepção tradicional de cunho jurídico e geográfica que representa a fronteira como extremidade de um país ou região do lado onde confina com outro, expressando a ideia de limite territorial (AURELIO, 2002), não pode dar conta de expressar a diversidade ou a multiplicidade de fenômenos decorrentes das especificidades $\mathrm{da}(\mathrm{s})$ fronteira(s). A fronteira não é uma só (OLIVEIRA, 2005). Ela (a fronteira) pode representar diversas situações, como nos aponta Martins (1997, p.11) “fronteira da civilização (demarcada pela barbárie que nela se oculta), fronteira espacial, fronteira de culturas e visões de mundo, fronteira de etnias, fronteiras da história e da historicidade do homem. E sobretudo, fronteira do humano".

Além dessas abordagens sobre fronteira, existe uma outra que desejamos explorar um pouco mais, que são as fronteiras da ciência moderna, pautada pela racionalidade científica.

\title{
3. Ciência, cartografia e fronteira
}

A própria ciência cria suas fronteiras (HISSA, 2006). Existe uma "mobilidade das fronteiras" do pensamento científico. Assim como, a evolução das sociedades humanas, ao longo dos tempos, fora constante e dinâmica alterando-se os valores, as crenças, as mitologias, enfim, as ideias acerca da realidade. Podemos afirmar que o mesmo ocorreu com a ciência.

As origens transdisciplinares do conhecimento científico estimulam a reflexão acerca de processos que se referem às negações e contradições da ciência. [...] o saber científico é transdisciplinar, feito de limites, mas, especialmente, de fronteiras que procuram a sua expansão. Fronteiras moventes. A mobilidade das fronteiras entre os saberes científicos, por sua vez, faz o movimento dos territórios 
disciplinares: mobilidades transgressoras, que subvertem o conhecimento para, permanentemente, fazê-lo buscar o saber (HISSA, 2007).

Para Boaventura de Sousa Santos, a ciência moderna fragmentou-se em diversas áreas do conhecimento e continua a se especializar cada vez mais. Para ele o

\begin{abstract}
Conhecimento [científico] é tanto mais rigoroso quanto mais restrito é o objeto sobre que incide. Nisso reside, aliás, o que hoje se reconhece ser o dilema básico da ciência moderna: o seu rigor aumenta na proporção direta da arbitrariedade com que espartilha o real. Sendo um conhecimento disciplinar, tende a ser um conhecimento disciplinado, isto é, segrega uma organização do saber orientada para policiar as fronteiras entre as disciplinas e reprimir os que as quiserem transpor (SANTOS, 1988, p.64).
\end{abstract}

A racionalidade humana (com o surgimento do Estado-nação) buscou na cartografia geográfica elementos de base científica para a elaboração de representações do "mundo real" (os mapas), que também representam o espaço delimitado pelos homens, ou seja, as fronteiras entre as Nações, tal qual, são conhecidas atualmente.

O geógrafo Cássio Hissa ao analisar o conto do escritor argentino Jorge Luís Borges "Sobre o rigor na ciência", que faz uma crítica do "extremo" rigor científico expresso em seu conto na cartografia realizada pela ciência moderna. Nesse sentido, " a ciência, assim, limitarse-ia ao dado coletado do mundo, como se ela pudesse ser o mundo" (HISSA, 2006, p.28). Pois a primazia do rigor na ciência na busca por objetividade, tem reduzido (e até mesmo eliminado) outras formas de "cartografar" o mundo, pautadas pela imaginação filosófica, mitológica, artística e literária que buscava uma interpretação simbólica do mundo.

A cartografia moderna eclodiu no período da Renascença. Acompanhando assim, o surgimento do Estado moderno. Rapidamente tornou-se um instrumento de poder em mãos dos "estadistas" modernos, privilegiando e associando-se ao pensamento euclidiano, contribuindo para modelar o comportamento do poder (RAFFESTIN, 1993). Revelando uma associação muito válida para a racionalidade cientifica, porque mobilizava três elementos fundamentais: "a superfície ou o plano, a linha ou a reta e o ponto ou momento o plano. É da combinação desses elementos que resultam as imagens ou as representações do espaço (RAFFESTIN, 1993, p.133).

As projeções de poder sobre um determinado espaço, através da delimitação de um território qualquer, a partir dos traçados, dos pontos, das escalas, enfim de métodos cartográficos, representam a materialização de um sistema de poder intencionalmente moldado sobre aquele território. Aqui entra a figura representativa dos mapas como

\footnotetext{
${ }^{2}$ BORGES. Jorge Luís. História universal da infâmia. 5. Ed. São Paulo: Globo, 1989, p.71.
} 

e-ISSN 2016/Atual: 2525-7870 | e-ISSN 2015/2016: 2447-018X

instrumento de poder e do "poder". Visto que, com o nascimento dos Estados modernos, os mapas tornaram-se ferramentas ideais para delimitar, demarcar e determinar os limites da(s) fronteira(s).

Parece-nos que o estabelecimento de limites é intrínseco a condição de nossa existência humana, através da sensação de que os limites estão presentes em diversas fases da nossa vida cotidiana. Pois "entrar em relação com os seres e as coisas é traçar limites ou se chocar com limites. Toda relação depende da delimitação de um campo, no interior do qual ela se origina, se realiza e se esgota". (RAFFESTIN, 1993, p.164). Estando associado ao poder "os limites [e fronteiras] também se vinculam às ideologias, à ética, às normas de comportamento" (HISSA, 2006, p.38).

Nesse contexto, podemos inferir que é a partir do estabelecimento de limites que a(s) fronteira(s) se constituem. As fronteiras, por sua vez, tal qual a concebemos em seu sentido convencional (ou pelo senso comum) como delimitação político-administrativa não existem, as fronteiras são criações humanas e estabelecem relações de poder. Assim, a manifestação da fronteira "é apenas uma abstração que, no cotidiano, manifesta-se através de sinais: a manifestação de poderes de diversas categorias" (HISSA, 2006, p.38).

Podemos perceber tal afirmação em Goettert (2011) que descreve as fronteiras como dispositivo de poder, de controle e de identidade, segundo o autor a " disposição das fronteiras nacionais no Mundo Moderno é a expressão dos poderes, dos controles e das identidades (...)" (GOETTERT, 2011, p.56), inspirado principalmente nos trabalhos de Poulantzas (1990), Foucault (1996) e Agamben (2009). Para melhor compreensão vejamos as imagens abaixo.
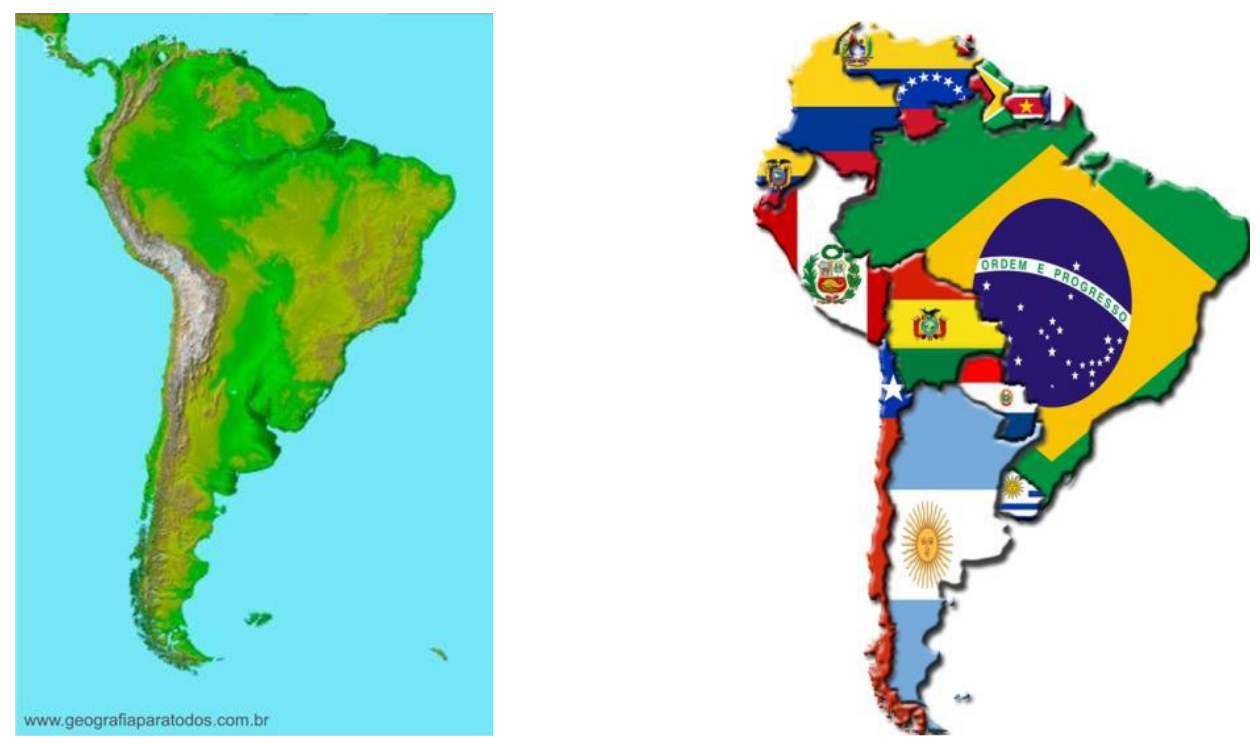
RELACult - Revista Latino-Americana de Estudos em Cultura e Sociedade

Revista Latinoamericana de Estudios en Cultura y Sociedad | Latin American Journal of Studies in Culture and Society

V. 02, Ed. Especial, dezembro, 2016, p. 533-546| periodicos.claec.org e-ISSN 2016/Atual: 2525-7870 | e-ISSN 2015/2016: 2447-018X

Imagem 1

Fonte: Geografia para todos, 2015.

\section{Imagem 2}

Fonte: Brasil escola, 2015.

As fronteiras assim descritas como representações de poder, fazem parte de "nossas produções imagéticas e representacionais" (GOETTERT, 2011, p.56), as imagens 1 e 2 "são ilustrativas de como o "espaço natural" é alçado a di-visões e fragmentações territoriais, discursivas e imagéticas, pretensamente neutras, naturalizadas" (GOETTERT, 2011, p.66). Na imagem 4 é visível a construção dos nacionalismos sendo enclausurados como dispositivo de fronteira.

A nacionalidade como fonte da identidade teria surgido da necessidade das comunidades modernas serem reconhecidas e terem algum conforto ante um mundo instável e indiferente, ou seja, compartilhar língua, cultura, tradições, história permite que pessoas reconheçam umas às outras, com a vantagem adicional de facilitar a cooperação e a proteção (MACHADO, 2005, p.247).

Baseadas nas concepções totalitárias dos Estados-Nacões, as representações cotidianas nos espaços de fronteiras reforçam a unidade das nacionalidades em conflito e robustecem os mecanismos de identidade únicas (GOETTERT, 2013).

\section{Giro na perspectiva pós-colonial de fronteira}

As abordagens do cientista político Boaventura de Souza, apesar de estarem indiretamente ligadas aos temas sobre fronteira, são de suma importância para este estudo. Pois, segundo ele, o delineamento cartográfico do mundo que demarca o velho e o novo mundo ainda persistem no pensamento moderno ocidental mantendo relações políticas e culturais excludentes (SANTOS, 2007).

Sendo que os territórios coloniais constituíam lugares impensáveis para o desenvolvimento do paradigma da regulação/emancipação, o facto de este paradigma lhes não ser aplicável não comprometeu a sua universalidade [...] As distinções intensamente visíveis que estruturam a realidade social deste lado da linha baseiam-se na invisibilidade das distinções entre este e o outro lado da linha (SANTOS, 2007, p.02).

Prosseguindo na linha de raciocínio desse autor, "o pensamento moderno ocidental continua a operar mediante linhas abissais que dividem o mundo humano do sub-humano" (SANTOS, 2007, p.08). O que caracteriza o mundo moderno ocidental são as linhas abissais que constituem o mundo social em dois universos, ou seja, um universo "deste lado da linha" e o universo "do outro lado da linha", este último, por sua vez, desaparece enquanto realidade viva social (SANTOS, 2007). 

e-ISSN 2016/Atual: 2525-7870 | e-ISSN 2015/2016: 2447-018X

As linhas abissais representam as desigualdades assimétricas culturais, sociais e de saberes referentes ao sistema mundial, pois "deste lado da linha" concentra-se o pensamento hegemônico moderno ocidental, tendo como modelo a civilização europeia (eurocentrista), pautadas na imagem do homem branco, cristão e heterossexual, e "do outro lado" estaria os "marginalizados", os sujeitos “desqualificados", vivendo em um mundo subalterno onde seus conhecimentos (saberes) são desconsiderados/inexistentes/anulados pelos que estão "deste lado da linha".

$\mathrm{Na}$ autoconsciência européia da modernidade, estas sucessivas separações se articulam com aquelas que servem de fundamento ao contraste essencial estabelecido a partir da conformação colonial do mundo entre ocidental ou europeu (concebido como o moderno, o avançado) e os "Outros", o restante dos povos e culturas do planeta (LANDER, 2005, p.04).

Em nossos dias atuais, ou mais precisamente, neste início do século XXI, ainda existe "uma colonialidade do saber e poder implicada na constituição desse sistema mundo" (PORTO-GONCALVES, 2011, p.02). E há séculos tem negado de forma arbitraria os saberes tradicionais das sociedades/tribos/comunidades que estão do "outro lado da linha":

Ao mesmo tempo em que os domínios climatobotânicos foram naturalmente se desenhando e nos oferecendo as geografias que hoje conhecemos, várias populações foram desenvolvendo um rico acervo de conhecimentos que, tal como a megadiversidade biológica, é também um patrimônio que a região abriga e que deve ser considerado tanto nas políticas de regionalização e ambiental, como cientifica e tecnológica. E trata-se de um patrimônio de conhecimento construído em grande parte numa relação com e não contra a natureza (...) (PORTO-GONCALVES, 2011, p.07).

Por isso, precisamos superar a colonialidade do saber que, marginaliza toda e qualquer compreensão do "outro" numa escala de inferioridade comparada com as possibilidades da sociedade ocidental eurocêntrica. Conforme, Lander (2005), devemos buscar alternativas a esta configuração do sistema mundial e isso exige um esforço de desconstrução das regras e normas impostas pela sociedade capitalista-liberal. As abordagens realizadas no sentido pós-colonial podem ser de grandiosa valia para uma melhor interpretação do mundo moderno na procura de conhecimentos não eurocêntricos. Podemos citar alguns autores que trabalham nesta perspectiva de análise pós-colonial, entre eles Walter Mignolo (Argentino), Aníbal Quijano (Peruano), Arturo Escobar (Colombiano), Ramón Grosfoguel (Porto-riquenho), Edgardo Lander (Venezuelano) e Carlos Walter PortoGonçalves (Brasileiro). Isso para ficar apenas com os "latino-americanos", já que existem outros autores da vertente "pós-colonialista" fora do continente americano e não foram aqui mencionados. 
RELACult - Revista Latino-Americana de Estudos em Cultura e Sociedade

Revista Latinoamericana de Estudios en Cultura y Sociedad | Latin American Journal of Studies in Culture and Society

V. 02, Ed. Especial, dezembro, 2016, p. 533-546| periodicos.claec.org e-ISSN 2016/Atual: 2525-7870 | e-ISSN 2015/2016: 2447-018X

A origem do termo pós-colonial foi cunhada pela primeira vez por historiadores no período pós-guerra devida a "descolonização" de diversos países que se tornaram independentes. A preocupação desses teóricos era, sobretudo, realizar análises sobre os processos de independência e as consequências herdadas pelo período colonial.

As abordagens realizadas por esses pensadores Latino-Americanos sobre os estudos pós-coloniais enfatizam as

relações assimétricas de poder e as possibilidades de traduções e hibridismo culturais como uma forma de crítica as visões presas aos purismos raciais, étnicos e nacionais. A tradução cultural polemiza com as tradições culturais inventadas e desafia o mundo pós-colonial. O hibridismo e a diferença cultural aparecem para muitos autores como uma forma de luta teórica e política diante dos discursos homogêneos da nação (ALBUQUERQUE, 2010, p.48).

Em suma, as abordagens pós-coloniais revelam duras críticas às noções de desenvolvimento, as formas de saberes eurocêntricos, as desigualdades entre os sexos, as hierarquias raciais, as desigualdades nas periferias do sistema-mundo, entre outros (GROSFOGUEL, 2008). Em contrapartida salientam os aspectos positivos das culturas não hegemônicas que ainda cultuam seus "velhos" saberes tradicionais.

Podemos citar alguns casos na América Latina de práticas e iniciativas que revelam êxitos na superação da "colonialidade dos saberes" ou em casos como na Universidade de Chiapas no México, ocorre uma articulação entre os saberes tradicionais e o conhecimento científico. Na medicina, na indústria farmacêutica, como em outros ramos da ciência moderna, os conhecimentos tradicionais de grupos indígenas foram e continuam sendo incorporados pelos pesquisadores.

La aceptación del multilingüismo en las escuelas de algunos países y la aparición de universidades indígenas indica cierto equilibrio entre lo tradicional y lo moderno. A veces, promovido por instituciones es tátales; en otros casos, se debe al ascenso de movimientos sociales que reivindican saberes no hegemónicos y buscan articularlos con las instituciones académicas. Lo comprueban Ecuador, México y Perú con el crecimiento de la matrícula de indígenas en universidades organizadas de acuerdo con el saber occidental moderno: por ejemplo, en la Universidad de Chiapas, en México, el 47\% de los estudiantes que ingresaron en 2003 declaraban ser hablantes de una lengua indígena (CANCLINI, 2005, p.183).

Ou seja, as formas de organização das tribos indígenas que por décadas mantiveram tradicionalmente suas culturas ou crenças, podem e devem coexistir com outras formas de organização sociais, mesmo as que são pautadas pela racionalidade científica.

Desde una concepción evolucionista podría verse como paradójico que instrumentos como la televisión e Internet contribuyan a la expansión de medicinas tradicionales. 
$\mathrm{O}$ que grupos indígenas utilicen programas de computación para registrar y dar continuidade a sus mitos y cosmovisiones. En realidad, ambos processos muestran la compleja interacción, a veces cooperativa, a veces conflictiva, que encontramos hoy entre formas antiguas y modernas, tradicicionales y científicas, de conocimiento CANCLINI, 2005, p.183).

No Brasil, iniciativas como a primeira Faculdade em aldeia indígena, localizada no município de Japorã/MS, são afirmações que possibilitam a coexistência das relações indígenas tradicionais em conjunto com o conhecimento científico. E possuem um caráter singular na tentativa de "quebrar" as fronteiras ou os limites impostos pelo conhecimento hegemônico (racional).

\section{Sobre fronteiras e pensamento fronteiriço}

Adimitindo-se que existe um mundo moderno "colonial" expresso por sua colonialidade do saber e poder como vimos anteriormente, e, reconhecendo uma profunda negligência de outros saberes, conhecimentos, culturas negadas pelas fronteiras do pensamento hegemônico (eurocêntrico). Nesse caso, ao aceitar essas proposições, podemos analisar a fronteira como o espaço-tempo limite entre o colonialismo e o pós-colonialismo, ou até mesmo "sugerir que momentos históricos e epistemológicos podem ser esta fronteira" (AUGUSTONI; VIANA, 2010, p.191). Isso sugere que o importante nesse processo são as implicações do momento fronteiriço do processo da descolonização que não ocorre instantaneamente e devem ser compreendidos como um palco, no qual, são exercidas relações de poder entre dominador e dominado (AUGUSTONI; VIANA, 2010).

Surge assim, a ideia de "pensamento fronteiriço" que Segundo o autor Mignolo (2003): "La idea del pensamiento fronterizo surgió para identificar el potencial de un pensamiento que surge desde la subalternidad colonial” (MIGNOLO, 2003, p.51). Seguindo na esteira desse autor, o pensamento fronteiriço representa um instrumento de descolonização intelectual, assim como também, de descolonização política e econômica. Ou seja, esse pensamento expresso por Mignolo significa a manifestação de uma ruptura emergente, capaz de combater o pensamento hegemônico desde uma perspectiva do subalterno. $\mathrm{Na}$ interpretação do autor Grosfoguel (2008, p.24) o pensamento crítico de fronteira é

a resposta epistémica do subalterno ao projeto eurocêntrico da modernidade. Ao invés de rejeitarem a modernidade para se recolherem num absolutismo fundamentalista, as epistemologias de fronteira subsumem/redefinem a retórica emancipatória da modernidade a partir das cosmologias e epistemologias do subalterno, localizadas no lado oprimido e explorado da diferença colonial, rumo a uma luta de libertação descolonial em prol de um mundo capaz de superar a modernidade eurocentrada. Aquilo que o pensamento de fronteira produz é uma 

e-ISSN 2016/Atual: 2525-7870 | e-ISSN 2015/2016: 2447-018X

redefinição/subsunção da cidadania e da democracia, dos direitos humanos, da humanidade e das relações económicas para lá das definições impostas pela modernidade europeia (GROSFOGUEL, 2008, p.24).

O pensamento fronteiriço - como aponta Grosfoguel (2010) - não é simplesmente um pensamento antimodernismo do mundo atual, ele é uma resposta descolonial dos povos/sujeitos subalternos perante a modernidade eurocêntrica. Um bom exemplo disso é a ação combativa contra as imposições da colonialidade do saber e poder realizadas pelo movimento zapatista, formado por camponeses e indígenas no México.

Os zapatistas não são fundamentalistas antimodernos, não rejeitam a democracia nem se remetem a uma espécie de fundamentalismo indígena. Pelo contrário, os zapatistas aceitam a noção de democracia, mas redefinem-na partindo da prática e da cosmologia indígena local, conceptualizando-a de acordo com a máxima "comandar obedecendo" ou "todos diferentes, todos iguais". O que parece ser um slogan paradoxal é, na verdade, uma redefinição crítica descolonial da democracia, recorrendo às práticas, cosmologias e epistemologias do subalterno. Isto leva-nos à questão de como transcender o monólogo imperial estabelecido pela modernidade europeia-eurocêntrica (GROSFOGUEL, 2008, p.24).

O movimento zapatista, insere-se nesse contexto pensamento fronteiriço porque representa a força/potência de uma organização que emergiu da subalternidade social imposta pela fronteira do pensamento hegemônico que deixou movimentos como este do "outro lado da linha". É um movimento fundamentalmente com aspirações políticas e militares pautadas na democracia como principal objetivo.

La geopolítica del conocimiento contribuye a abrir los ojos, correr las cortinas y ver que un paradigma otro está surgiendo en y desde los márgenes. En África, tanto en el sur como en el norte; en la región afrocariberia; en los movimientos indígenas; en Asia del Sur, etc. "Un paradigma otro" que surge en las zonas tanto de subalternidad colonial (Áfnca, Asia meridional, América Latina) como de subalternidad imperial (el sur de Europa). El agotamiento de los ideales de la segunda modernidad (la Ilustración y el pensamiento dominante durante tres siglos de Francia, Inglaterra, Alemania, Estados Unidos) entra en proceso terminal (...) (MIGNOLO, 2003, p.58).

O pensamento fronteiriço ou pensamento crítico de fronteira, deve partir da geopolítica do conhecimento das populações "marginalizadas", em geral, como uma crítica da ideologia da modernidade, do desenvolvimento, do progresso, da racionalidade científica, entre outros. Para dar espaço a outros tipos de conhecimento/pensamentos/saberes do mundo que vêm sendo negado por décadas de colonialismo e imperialismo global. Assim, buscar uma coexistência entre as múltiplas formas de saberes visando - segundo Porto-Goncalves (2011) - uma integração com justiça social. 


\section{Considerações finais}

Os limites impostos entre as fronteiras e Nações, constituindo as fronteiras nacionais, são meramente criações humanas, delimitadas e impostas por processos de ocupação demográfica, política, econômica, cultural na formação dos territórios (ALBUQUERQUE, 2010).

A fronteira é o lugar do distinto, do diferente, do singular, do distante, do próximo, do encontro entre o que distância e aproxima o "eu" do "outro". Na fronteira, não existe um espaço e tempo linear. O que existe são vários tempos e vários espaços (MONDARDO, 2008). Nesse sentido, consideramos a fronteira como a linha que separa o "eu" do "outro", no sentido em que percebemos ou nos relacionamos com o "outro".

Uma situação de fronteira, deve ser pensada "não só em relação à questão de alteridade, mas também em relação à questão das definições culturais do limite do humano pelos diferentes grupos sociais e étnicos que a fronteira põe em confronto" (MARTINS, 1997, p.32).

Também podemos analisar a fronteira como o espaço-tempo limite entre $\mathrm{o}$ colonialismo e o pós-colonialismo. As abordagens realizadas no sentido pós-colonial podem ser de grandiosa valia para uma melhor interpretação do mundo moderno na procura de conhecimentos não eurocêntricos.

Para Santos (2006) o pós-colonialismo pode ser apreendido em duas definições principais. A primeira é referente a um período histórico, que sucedeu à independência das colônias, e a segunda diz respeito a um conjunto de práticas e discursos que desconstroem a história colonial descrita pelo colonizador e tenta substitui-la por histórias do ponto de vista do colonizado.

Na perspectiva do autor Walter Mignolo, desde o século XVI na América Latina, a colonialidade do poder tem ordenado e controlado a diferença cultural, racial, religiosa e linguista, de acordo com uma geopolítica do conhecimento, concedendo poderes máximos aos que estão no "centro" do sistema mundial, negando e descaracterizando as práticas e saberes dos que estão nas "margens" ou "periferias". Trata-se de uma dominação que não requer dominação física, pois nutre-se apenas da violência epistêmica que representa a naturalização da cultura ocidental como o único paradigma existente para as tomadas de decisões políticas, econômicas, culturais e cientificas (MIGNOLO, 2007). 


\section{Referências}

AGAMBEN, Giorgio. O que é o contemporâneo? e outros ensaios. Chapecó: Argos, 2009.

ALBUQUERQUE, José Lindomar. Fronteiras múltiplas e paradoxais. Textos \& Debates, Boa Vista - Roraima, v. 22, p.71-87. 2012. Semestral. Disponível em: <http://revista.ufrr.br/index.php/textosedebates/article/view/1605/1135>. Acesso em: 30 jul. 2015 .

AURELIO. Minidicionário de língua portuguesa. 4a edição revista e ampliada do minidicionário Aurélio. 7a impressão - Rio de Janeiro, 2002.

AUGUSTONI, Prisca; VIANA, Anderson Luiz. A identidade do sujeito na fronteira do póscolonialismo em Angola. Ipotesi, Juiz de Fora, v. 14, n. 2, p.189-205, 2010. S. Disponível em: <http://www.ufjf.br/revistaipotesi/files/2011/04/16-A-identidade-do-sujeito-na-fronteirado-pós-colonialismo-em-Angola.pdf >. Acesso em: 15 jul. 2015.

CANCLINI, Néstor García. Diferentes, desiguais e desconectados: mapas da interculturalidade. Tradução Luiz Sérgio Henriques. Rio de Janeiro: UFRJ, 2005. 283p.

FOUCAULT, Michel. A microfísica do poder. 12 ed. Rio de Janeiro: Edições Graal, 1996.

. Vigiar e punir. 35 ed. Petrópolis: Vozes, 2008b.

GOETTERT, Jones Dari. Fronteiras na fronteira: 'falas atravessadas' entre Brasil e Paraguai. Revista Geonorte, v. 7, p. 748-766, 2013.

GOETTERT, Jones Dari. A fronteira como dispositivo de poder, de controle e de identidade (considerações iniciais). Geografia em Questão (Online), v. 4, p. 56-71, 2011.

GROSFOGUEL, Ramón. "Para descolonizar os estudos de economia política e os estudos pós-coloniais: transmodernidade, pensamento de fronteira e colonialidade global". Revista Crítica de Ciências Sociais, n. 80, p. 115-147. 2008.

HAESBAERT, Rogério. Descontrole dos Territórios (e de suas Fronteiras) num Mundo Globalizado. Geografia em Questão Agrária. M.C. Rondon. V.1, n. 2. p. 56-69. 2009.

HANNERZ, Ulf. Fluxos, fronteiras, híbridos: palavras-chave da antropologia transnacional. Mana[online]. 1997, vol.3, n.1, pp. 7-39.

HISSA, Cássio Eduardo. V. A mobilidade das fronteiras: inserções da Geografia na crise da modernidade. Belo Horizonte: Ed. Da UFMG, 2006, p. 19-111 e 159-198.

HISSA, Cássio Eduardo. Fronteiras entre ciência e saberes locais: arquiteturas do pensamento utópico. In: IX Colóquio Internacional de Geocrítica: los problemas del mundo actual. Soluciones y alternativas desde la geografía y las ciencias sociales. Porto Alegre, $28 \mathrm{de}$ mayo - 1 de junio de 2007. Universidade Federal do Rio Grande do Sul.

HOUAISS. Dicionário Eletrônico. Rio de Janeiro: Objetiva: 2007.CD-ROM. 
LANDER, Edgardo. Ciências sociais: saberes coloniais e eurocêntricos. 1 ed. Buenos Aires: Consejo Latinoamericano de Ciências Sociales - CLACSO, 2005. 280 p.

MACHADO, Lia Osorio. Sistemas, Fronteiras e Território. Rio de Janeiro: Grupo Retis/UFRJ, 2002.

MACHADO, Lia Osório. Estado, territorialidade, redes. Cidades gêmeas na zona de fronteira sul-americana. Em: María Laura Silveira (Org.). Continente em chamas. Globalização e território na América Latina. Rio de Janeiro: Civilização Brasileira, p. 285284. 2005.

MACHADO, Lia Osorio. "Limites, Fronteira e Redes", In Strohaecker e outros (orgs), Fronteiras e Espaço Global, Porto Alegre, AGB, 1998, p. 41-49.

MARTINS, José de Souza. Fronteira: a degradação do Outro nos confins do humano. São Paulo, SP: HUCITEC, 1997.

MIGNOLO, Walter. Historias locales/diseños globales. Colonialidad, conocimientos subalternos y pensamiento fronterizo Akal, Madrid, 2003.

MIGNOLO, Walter. La idea de América Latina: la herida colonial y la opción decolonial. Barcelona: Gedisa Editorial, 2007.

MONDARDO, Marcos Leandro. Identidades na fronteira (trans)territorial entre Brasil e Paraguai: olhares das relações de contato e de contraste. Tempos Históricos (EDUNIOESTE), v. 12, p. 1-30, 2008.

OLIVEIRA, Tito Carlos Machado de. Tipologia das relações fronteiriças: elementos para o debate teórico-prático. In: (Org.). Território sem limites: estudos sobre fronteiras. Campo Grande: EdUFMS, 2005, p. 377-408.

POUlantZAS, Nicos. O Estado, o Poder, o Socialismo. 3 ed. Rio de Janeiro: Edições Graal, 1990.

PORTO-GONÇALVEZ, Carlos Walter. Ou inventamos ou erramos: encruzilhadas da integração regional Sul-americana. Pesquisa desenvolvida no Projeto PNPD n. 15/2010: Governança Global e Integração da América do Sul (Instituto de Pesquisa Econômica Aplicada (IPEA) / Programa de Pesquisa para o Desenvolvimento Nacional - PNPD). 2011.

SANTOS, Boaventura de Sousa. Entre próspero e caliban: colonialismo, pós-colonialismo e inter-identidade. In: A gramática do tempo: para uma nova cultura política. São Paulo: Cortez, 2006. Capítulo 7, p. 227 - 276. (Coleção para um novo senso comum; v. 4).

SANTOS, Boaventura de Sousa. Para além do pensamento abissal: das linhas globais a uma ecologia dos saberes. In: SANTOS, Boaventura de S. MENEZES, Maria P. (Orgs). Epistemologias do Sul. Coimbra: Almedina, 2009, p.23-72. 
RELACult - Revista Latino-Americana de Estudos em Cultura e Sociedade

Revista Latinoamericana de Estudios en Cultura y Sociedad | Latin American Journal of Studies in Culture and Society V. 02, Ed. Especial, dezembro, 2016, p. 533-546| periodicos.claec.org e-ISSN 2016/Atual: 2525-7870 | e-ISSN 2015/2016: 2447-018X

SANTOS, Boaventura de Sousa. Um discurso sobre as ciências na transição para uma ciência pós-moderna. Estudos Avançados vol.2 no.2. São Paulo, May/Aug. 1988. http://dx.doi.org/10.1590/S0103-40141988000200007.

\section{Fonte das Imagens}

\section{Imagem 1}

http://www.geografiaparatodos.com.br/img/mapas_fisicos/america_do_sul_fisico.jpg (acessado em 16/06/2015)

\section{Imagem 2}

http://www.brasilescola.com/geografia/america-sul.htm (acessado em 16/06/2015) 